Educ. Sci. 2014, 4, 13-35; doi:10.3390/educsci4010013

Article

\title{
Cultivating Reflective Practitioners in Technology Preparation: Constructing TPACK through Reflection
}

\section{Liangyue Lu ${ }^{1,2}$}

1 Educational Leadership Department, Grambling State University, Grambling, LA 71245, USA

2 Department of Instructional Design, Development and Evaluation, Syracuse University, 330 Huntington Hall, Syracuse, NY 13244, USA; E-Mail: 1lu02@syr.edu;

Tel.: +1-614-522-9880; Fax: +1-614-887-8740

Received: 19 September 2013; in revised form: 3 December 2013 / Accepted: 9 December 2013 / Published: 27 December 2013

\begin{abstract}
Teaching is a complex profession, which is further complicated by the integration of technology into classrooms. Reflection can help teachers unpack the complexity in their practice. Reflection can be an effective instructional strategy in helping preservice teachers develop technological pedagogical content knowledge (TPACK), the complex and dynamic knowledge necessary for effective technology integration into instruction. In this study, reflective activities were integrated into a Learning By Design (LBD) environment, which was created to help preservice teachers develop TPACK. This paper investigated the participants' TPACK development and examined how reflection helped them construct TPACK. Through content analysis of the participants' reflective journals, the researcher found that the preservice teachers developed initial TPACK awareness. However, their reflection in technology knowledge and the content aspects of TPACK were limited and superficial. Interviews with the participants showed reflection helped the preservice teachers remember what they learned by describing and elaborating on their in-class experiences, pushed them to think about how to apply what they learned in their future classrooms, and helped them become more reflective and open-minded about using technology in classrooms. Finally, the researcher discussed this study's implications for teacher educators and researchers.
\end{abstract}

Keywords: TPACK; preservice teachers; reflection; technology preparation 


\section{Introduction}

Teaching is a complex profession that is full of "uncertainty, instability, uniqueness, and value conflict" ([1], p. 49). Teachers often deal with ill-defined problems in classrooms and solving those problems often requires artistry and intuition, as well as technical expertise [1]. In the Digital Age, teaching is further complicated by the integration of information and communication technology in classrooms. More and more scholars have acknowledged that the knowledge essential for effective technology integration in instruction, which is also known as technological pedagogical content knowledge (TPACK), is "complex, multifaceted, and situated" ([2], p. 1017). Similar to the development of other teacher knowledge, the development of TPACK in preservice teachers requires opportunities for them to grapple with its inherent complexity. Since reflection is essential for preservice teachers to identify, analyze, manage and solve the many complex teaching problems [3], the researcher suggested reflection can be a potential strategy to help preservice teachers disentangle the complex and dynamic relationship to and the intricacies of integrating content, pedagogy, and technology in TPACK development.

Scholars have discussed using reflection to facilitate preservice teachers' knowledge development (e.g., [4]) or using technology to foster preservice teachers' reflection (e.g., [5,6]). However, fewer studies have discussed whether and how reflection can help preservice teachers develop knowledge about teaching with technology. In this study, reflective activities were integrated into a Learning By Design (LBD) environment, which was created to help teachers develop TPACK based on suggestions from the literature (e.g., [7,8]). In the learning environment, the preservice teachers used reflection to interpret their technology integration experience in the classroom and foster their TPACK construction. The researcher investigated the preservice teachers' TPACK development as manifested in the reflection on their technology integration experience and interviewed them about their opinions on the reflective activities. Through content analysis of the preservice teachers' reflective journals and thematic analysis on the interviews, two questions were explored in this study:

a. How did the preservice teachers interpret their in-class technology integration experience?

b. How did reflection help the preservice teachers develop TPACK?

\subsection{Reflection in Teacher Preparation}

Following Schön's seminal work in 1983, researchers have established the role of reflection as an important strategy in teacher knowledge development (e.g., [9]). This section discusses the definition of reflection, the result of reflection, and teaching reflection through journal writing.

The ideas behind many reflective practices in today's teacher education can be traced back to the "key originator" ([9], p. 33), John Dewey. Dewey holds that a reflective thought is the "[a]ctive, persistent, and careful consideration of any belief or supposed form of knowledge in the light of the grounds that support it and the further conclusions to which it tends" ([10], p. 9). Schön extended Dewey's idea by describing reflection in two categories: reflection-in-action and reflection-on-action [1]. Reflection-in-action requires practitioners to construct a new understanding toward an uncertain and unique situation that will guide action while the situation is unfolding during action. Reflection-on-action is an afterthought about actions taken in a situation. By definition, reflection is inseparably connected 
with action, and scholars tend to be more concerned with reflection leading to a "modified action" ([9], p. 34). Thus, one benefit of reflection in relation to teaching is that it helps teachers "think about how to apply the knowledge they received in their training programs and past experiences to make changes in their instruction" ([11], p. 241).

Although a "modified action" is the desired result of reflective practices, reconstructed practical theory about teaching and learning is often the result of reflection [12]. Reflection may not lead to immediate action or problem solving [13]. Its essential nature is "thinking about action" ([9], p. 34). As Dewey put it, "[t]o reflect is to look back over what has been done so as to extract the net meanings which are the capital stock for intelligent dealing with further experiences" ([14], p. 110). Central to reflective practices are personal and professional experiences, which lead to the construction of practical knowledge $[15,16]$. Practical theory, the strongest determining factor in a teacher's educational practice, is established through a series of diverse events, such as practice experience, reading, listening, and looking at other people's practices [17]. Practical theory is often tacit $[1,15,18]$. The role of reflection is to help preservice teachers make their practical theory explicit by clarifying and extending it $[12,15]$. Reflection can help preservice teachers "to unpack their own experiences, beliefs, knowledge and philosophies and to help them understand how these shape their identities and actions as teachers" ([19], p. 1125]).

When describing, analyzing, and making inferences about classroom events, teachers are constructing their own theory about teaching [16]. However, teachers need to learn analytical thinking skills involved in reflective activities [3,10,12]. Journal writing is a popular pedagogical strategy to elicit reflective thoughts from preservice teachers (e.g., [3,12]). Research found that reflective journal writing can contribute to the development of teachers' reflective thinking $[3,12]$. Through construction and reconstruction of their experiences and stories, teachers can raise their voices [13] and develop deeper understanding of their own experiences [16].

As a strategy for teacher knowledge development, reflection engages teachers to think about their teaching practices. These reflective practices often lead to teachers' reconstructed practical theory about teaching and learning. Reflective thinking needs to be taught and can be taught through journal writing $[3,10,12]$. The next section discusses why reflection can be a potentially effective strategy to help preservice teachers develop TPACK.

\subsection{Reflection in TPACK Development}

As an inseparable component of a teacher's overall knowledge base, teachers' knowledge about technology integration is also complex, situated, and multifaceted [2]. The TPACK framework proposed by Mishra and Koehler captures the essential knowledge for effective technology integration in classrooms [2]. Mishra and Koehler argued that the essence of teachers' knowledge about technology integration lies at the center of the framework, the interplay of content knowledge, pedagogical knowledge and technology knowledge. Mishra and Koehler defined the meaning of each TPACK component by describing the key questions and concerns in each (see Table 1). 
Table 1. Definition of technological pedagogical content knowledge (TPACK).

\begin{tabular}{|c|c|}
\hline TPACK & Definition \\
\hline Technology knowledge (TK) & Knowledge about standard technologies and more advanced technologies. \\
\hline Pedagogical knowledge (PK) & $\begin{array}{l}\text { Deep knowledge about the processes and practices or methods of teaching and } \\
\text { learning and how this knowledge encompasses overall educational purposes, values, } \\
\text { and aims. }\end{array}$ \\
\hline Content knowledge (CK) & Knowledge about the actual subject matter being taught. \\
\hline $\begin{array}{l}\text { Technology pedagogical } \\
\text { knowledge (TPK) }\end{array}$ & $\begin{array}{l}\text { Knowledge of the various technologies used in teaching and learning settings, and } \\
\text { how teaching and learning might change as the result of using particular technologies. }\end{array}$ \\
\hline $\begin{array}{l}\text { Technology content knowledge } \\
\text { (TCK) }\end{array}$ & $\begin{array}{l}\text { Knowledge about the manner in which the subject matter can be changed by the } \\
\text { application of technology. }\end{array}$ \\
\hline $\begin{array}{l}\text { Pedagogical content knowledge } \\
\text { (PCK) }\end{array}$ & $\begin{array}{l}\text { Knowledge of what teaching approaches fit the content and how elements of the } \\
\text { content can be arranged for better teaching. }\end{array}$ \\
\hline $\begin{array}{l}\text { Technological pedagogical } \\
\text { content knowledge (TPACK) }\end{array}$ & $\begin{array}{l}\text { Knowledge of the representation of concepts using technologies; pedagogical } \\
\text { techniques that use technologies in constructive ways to teach content; knowledge of } \\
\text { how technology can help redress the difficulties that students face in learning; } \\
\text { knowledge of students' prior knowledge and theories of epistemology, how } \\
\text { technologies can be used to build on existing knowledge and to develop new } \\
\text { epistemologies or strengthen old ones. }\end{array}$ \\
\hline
\end{tabular}

Note: This table was adapted from Mishra and Koehler's paper, Technological pedagogical content knowledge: A framework for teacher knowledge [2].

To help teachers develop TPACK, Learning By Design has been proposed as a promising instructional approach $[7,8]$. It is a project-based, learner-centered instructional model that engages learners in designing artifacts for a real-world context, whereby learners construct their understanding and meaning toward a topic or concept [20]. Learners in an LBD environment should be given opportunities to develop and implement their ideas, receive feedback, articulate their reasoning, reflect on their experiences, refine their ideas, and relate to their prior experiences in order to solve new problems [21]. When used for technology integration training, LBD offers opportunities for teachers to use technology in authentic problem-solving contexts and to explore "the rich connections between technology, the subject matter (content), and the means of teaching it (the pedagogy)" ([7], p. 95). These learning experiences, addressing the situated nature and complex interplay of technology, pedagogy, and content, are deemed essential to the development of TPACK.

LBD entails using strategies to help learners construct understanding of their own work, through which they develop the knowledge integral to the problem-solving process, which, in this case, is TPACK. Reflection can provide opportunities necessary for preservice teachers to articulate their LBD experiences, through which they can further interpret their technology use experience and construct their practical theory about using technology for instruction. The ultimate goal of learning is that learners can apply what they have learned in new situations. Successful transfer of knowledge to new situations depends on two conditions "(a) the extent to which the old situation was interpreted and its lessons learned were articulated and recorded and (b) the accessibility of the old situation when the new one is encountered" ([22], p. 63). The better a piece of old experience is indexed, the more accessible it is when encountering new situations. Indexing is key to reusing what has been learned in one's experience [21]. Therefore, for preservice teachers to use TPACK in new contexts, having 
experiences in teaching with technology is not sufficient. Teachers must be given opportunities to reflect on those experiences so that they can "extract and clearly articulate what they have learned", "make those articulations rich in the right ways", and "index their experiences well" ([22], p. 63). When articulating what they have learned in LBD, preservice teachers also have to encounter the complexity of technology use in authentic teaching contexts, thus developing a deeper understanding of the complex and dynamic relationship of content, pedagogy, and technology in TPACK.

Thus, based on the above review of the literature, the researcher suggests that in order to construct their own understanding of TPACK, preservice teachers can use reflection in LBD to interpret and analyze their technology integration experience, and integrate it into their overall knowledge base.

\section{Research Design}

\subsection{Research Setting}

The research setting was a mandatory face-to-face technology integration course in a teacher preparation baccalaureate degree program in the School of Education at a large private northeastern university in the United States. Designed for preservice teachers who were in their initial stage of teacher training and who had little practical experience with classroom technology use, the course covered some general information technologies for teaching purposes, including educational websites, Microsoft Word and PowerPoint, Microsoft Excel, electronic communication tools, and assistive technologies. This course was carefully designed as an LBD environment, which was described in detail in another paper by the design and teaching team [23]. The course consisted of six classes. The first five classes included four routine instructional components: Reading discussions, model lessons, mini-projects, and reflections. In the first five classes, instructors first demonstrated live examples of effective technology use for teaching, while preservice teachers acted as K-12 students in the demonstration [24]. Then in the project section, preservice teachers used one technology to design an instructional product or an instructional solution to a real-world teaching task. After each of the first five classes, the preservice teachers were required to write a minimum of one-paragraph journal, reflecting on their in-class learning experience within 24 hours of the class. In the final class, preservice teachers conducted a group course project, teaching their fellow preservice teachers a fifteen-minute lesson using technology. The reflective activity in this paper refers to the writing of the reflective journals after the first five classes.

The overall goal of having the preservice teachers write reflective journals was to help them construct their own understanding of TPACK. To achieve this goal, each of their reflective journals was guided by the following questions: (1) What did you learn today about technology integration? (2) What instructional and classroom management strategies did you observe? (3) How did what you learned apply to what you already knew or are learning in other courses? (4) How might you apply what we did in class today for your future students? (5) What other questions or related thoughts would you like to ask or share?

Questions (1) and (2) were intended to help the preservice teachers interpret and analyze their technology integration experience in LBD. In the course, the instructors demonstrated many instructional strategies, especially classroom management strategies during their modeling. Therefore, 
the instructors asked the preservice teachers to also focus on reflecting on those strategies. Question (3) was intended to urge the preservice teachers to connect their technology integration experience to their previously acquired knowledge about teaching. Question (4) asked the preservice teachers to use their reconstructed experience to contemplate on how to solve teaching problems in their future classrooms. The final question gave the preservice teachers an opportunity to ask questions after taking the classes.

\subsection{Data Collection}

Data were collected from 39 preservice teachers who enrolled in this technology integration course. They were enrolled in teacher education programs as freshmen $(82 \%)$ or sophomores $(18 \%)$, and a majority of them (92\%) were female. Most of them had little to no teaching experience. The participants yielded 39 sets of reflective journal entries, of which 31 sets were complete, each having five journal entries. The remaining eight sets each had four journal entries. The researcher also interviewed the participants individually. She asked the participants about their opinions on the Learning By Design environment. One of the questions was whether reflection was helpful for them to understand teaching with technology and why they thought so. The analyses of the interviews were based on the 38 successfully recorded ones. In this study, the researcher only analyzed the participants' responses to the question about the reflective activities.

\subsection{Data Analysis}

To answer the first question, how the participants interpreted their in-class technology integration experiences, content analysis was conducted on the 39 sets of reflective journals using NVivo 8, qualitative analysis software. Content analysis is "a research technique for the objective, systematic, and quantitative description of the manifest content of communication" ([25], p. 18). It involves "comparing, contrasting, and categorizing a corpus of data" ([26], p. 40). Content analysis has been used to analyze teachers' technology integration experiences (e.g., [27,28]). For example, Koehler and his colleagues used content analysis to analyze the participants' activities and experiences in a faculty development design seminar to investigate their TPACK development [27].

Content analysis has three essential steps [27,29]. Firstly, researchers identify samples of textual materials, such as field notes, interview transcripts, and observation. In this study, the samples were all the preservice teachers' reflective journals about their learning experiences in the technology integration course. Secondly, researchers develop a protocol and train coders to use the protocol to identify and categorize the target variable. In this study, the target constructs were TPACK and its subsets. The researcher used Mishra and Koehler's definition of TPACK as the protocol. Thirdly, after coding the samples, researchers analyze and describe the target variable. As Schwandt [26] explains, "[c]ontemporary forms of content analysis include both numeric and interpretive means of analyzing data" (p. 40). In this study, in order to draw a comprehensive picture of the preservice teachers' current TPACK development, the author used both quantitative and qualitative analyses to interpret the preservice teachers' reflection on their technology integration experiences [27].

To investigate the preservice teachers' TPACK development, the researcher followed the three steps of content analysis to dissect the participants' technology integration experiences in their reflective journals. The TPACK framework was adopted as an analytical lens. The definition of 
TPACK constructs defined by Mishra and Koehler ([2], see Table 1) was used as the protocol to categorize the participants' experiences. The researcher and a coder first used two sets of reflective journals to develop coding examples for identifying the TPACK constructs (see Table 2). The category of content knowledge did not emerge in this study. Therefore, the coding examples presented here consist of only six categories. To ensure coding validity, the researcher and the coder coded each reflective journal independently. They then compared their codings until most coding differences were resolved through discussions. The final inter-rater agreement between the researcher and the coder was calculated using Nvivo. Table 3 lists the Cohen's Kappa values on the seven constructs, all of which are above 0.90 . In each TPACK construct, the researcher used the constant comparative method to identify themes about how the participants interpreted their technology integration experiences. By doing so, the researcher could detect themes about the participants' TPACK development from different angles by grouping their experiences into the seven TPACK components.

Table 2. TPACK Coding Categories.

\begin{tabular}{cl}
\hline TPACK Construct & \multicolumn{1}{c}{ Coding Example } \\
\hline TK & $\begin{array}{l}\text { Today in class we learned about creating spreadsheets on excel to use as a tool to collect data and } \\
\text { create charts. }\end{array}$ \\
\hline PK & $\begin{array}{l}\text { She also explained about a Jigsaw activity in which students are responsible for different parts of } \\
\text { an assignment and they all have to come together to make the whole. I have learned about this } \\
\text { strategy in Block 1 and have seen it done in my 2nd grade field experience this semester. }\end{array}$ \\
\hline I think that using centers at the computers could definitely be an effective strategy when you want \\
students to develop a large range of knowledge about a particular topic. After using all the \\
different websites, I now know to look for interactional websites that have instructions in multiple \\
forms such as audio, pictures, and words.
\end{tabular}

Table 3. Inter-rater Agreement.

\begin{tabular}{cccccccc}
\hline Construct & CK & PK & TK & TPK & PCK & TCK & TPACK \\
\hline Kappa & 1 & 0.95 & 0.98 & 0.91 & 0.97 & 0.92 & 1 \\
\hline
\end{tabular}


To answer the second question, how reflection helped the participants develop TPACK, the researcher used thematic analysis to investigate the data from the interviews with the preservice teachers. According to Braun and Clarke [30], thematic analysis is "a method for identifying, analyzing and reporting patterns (themes) within data. It minimally organizes and describes your data set in (rich) detail" (p. 79). It has six phases: (1) Becoming familiar with the data; (2) generating initial codes; (3) searching for themes; (4) reviewing themes; (5) defining and naming themes; (6) producing the report. The essential step is to identify a theme which "captures something important about the data in relation to the research question and represents some level of partnered response or meaning within the data set" ([30], p. 82). Following the six phases of thematic analysis, the researcher identified themes to interpret and explain the participants' narratives of their opinions on the reflective activity, that is, whether and why they thought reflection helped them develop a deeper understanding of their learning.

\section{Results and Discussion}

This section presents and discusses the findings from analyzing the participants' reflective journals and interviews. The analyses of reflective journals focused on how the preservice teachers interpreted their in-class technology integration experiences. The analyses of the interviews focused on determining how reflection helped the participants construct TPACK.

\subsection{Evidence of TPACK Growth}

To analyze the participants' interpretation of their technology integration experience, the researcher dissected their reflection using the TPACK framework and identified the coverage of each TPACK construct in their reflective journals. Coverage of a TPACK construct referred to the percentage of that construct coded in the 39 sets of the reflective journals, as shown in Figure 1. TPK (57.4\%), PK (14.64\%), and TPACK (12.8\%) were covered the most. The total coverage of TPK, PK, and TPACK was $84.84 \%$. The coverage of TK, $3.56 \%$, ranked fourth; TCK $(1.35 \%)$, PCK $(0.71 \%)$, and CK $(0 \%)$ had very low coverage.

Figure 1. Coverage of each TPACK construct in the reflective journals.

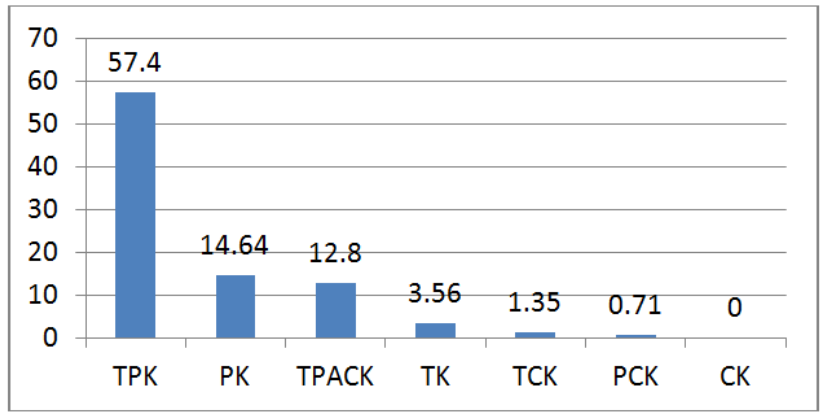

If the coverage of each TPACK construct is viewed as an indicator of the preservice teachers' knowledge growth, these results are generally consistent with the participants' self-assessment of their TPACK growth in another study [31]. In that study, the same group of participants' TPACK growth 
was measured by pre- and post-TPACK surveys before and after the participants had taken the same course. The results showed the participants' TPK, PK, TPACK, PCK, and TCK increased significantly after they had taken the course. As the participants felt their TPK, PK, TPACK increased, they reflected more on them in their reflective journals. Therefore, coverage of each TPACK construct in the participants' reflective journals can be a good indicator of their TPACK growth. In the following sections, how the preservice teachers articulated their understanding of technology integration in each TPACK construct is described, and a picture of their initially developed TPACK is sketched.

\subsection{Rich Reflection in TPK, PK, and TPACK}

As was found in the literature, preservice teachers can interpret their experience and construct their practical knowledge by articulating their experience in reflection $[15,16]$. Likewise, content analyses of the participants' journals in the current study showed they were able to articulate their understanding of TPACK with great detail by vividly describing their in-class technology integration experiences, especially in their reflection of TPK, PK, and TPACK. The participants' rich reflection may indicate that the preservice teachers have developed initial awareness in these three areas. As one preservice teacher stated, "If you can retell it, you have learned it!"

\subsubsection{TPK}

According to Mishra and Koehler [2], TPK is the knowledge of the various technologies used in teaching and learning settings, and how teaching and learning might change as a result of using particular technologies. The researcher and the coder coded TPK whenever the preservice teachers described their in-class experiences about how to use a technology tool for a learning activity, or when they envisioned how they would use technology for learning activities in their future classrooms. In the journals, TPK was reported to have the highest coverage among all the TPACK constructs. All 39 participants covered TPK in their journals. They described the impact of technology on teaching and learning, and explained how technology helped their students learn. Although the preservice teachers demonstrated positive attitudes toward using technology for teaching, they began to understand the complexity of technology integration in a K-12 classroom.

First, the participants began to understand how technology use influenced instruction. In the model lessons, the participants developed a positive attitude about using technologies in K-12 classrooms when they acted as K-12 students and observed the impacts of technology use on them. For example, Beth reflected on the class in which the class had a live video conference with a first-grade teacher and an elementary school librarian and wrote about how video conferencing can have an impact on classroom teaching.

Today we had an interactive web chat with teachers who told us about their technology integration. It was cool because it brought the teachers in our classroom because they couldn't physically be present. It was also a great way to show that even if you can't get a hold of a speaker, or be able to go on a field trip that you can still bring it into the classroom.

When the preservice teachers participated in the technology-integrated activities, they experienced the impact that technology use can have on teaching and learning. In her reflection, Beth understood 
that video conferencing can broaden students' learning resources by bringing in speakers who cannot physically be present in a classroom or by virtually bringing students to places where they cannot physically go. The awareness of technology's positive impact on teaching and learning was a sign of her beginning construction of TPK. According to Mishra and Koehler, TPK is the knowing of how teaching and learning might change as the result of technology use [2].

Second, the preservice teachers tried to explain from a teacher's perspective why using technology tools can be effective in a classroom. Evan discussed using web resources with students in different age groups.

The first IDE class was very interesting and made me more aware of how technology is and should be used with different aged kids. I learned that little kids in elementary school need more interactive activities such as games on computers...establishing a lesson with engaging activities on, for example, the alphabet [game], will make learning fun. I realize older kids can deal more with research-based activities such as the one we did in class with comparing and contrasting modern versus colonial life.

Knowing why and how one type of technology is effective for learning can not only help preservice teachers choose appropriate technology tools in a learning scenario, but can also help them choose proper instructional strategies consistent with a tool's affordance [2]. In Evan's case, he was able to explain from a teacher's perspective why using Internet resources in a classroom can be effective. As Evan reflected in his journal, after he experienced using Internet resources to learn as a K-12 student, he tried to show how Internet resources helped his students learn. He recognized that teachers could choose from a wide range of Internet resources for students in different age groups.

Third, although the preservice teachers were generally positive about technology use in classrooms, they started to understand the complexity of technology integration in a K-12 classroom. For example, Tracy was concerned that elementary students may be too young for some computer activities. She reflected on a model lesson, in which the students were asked to recreate a PowerPoint storybook after listening to a story.

It was also different to see a book being brought into a more active lesson. This feels like it could be tricky though because the book we read was for a younger demographic that might not be very good at typing quite yet...I know I didn't learn how to type well until I was around 11 so if I was that young child I would have gotten very frustrated.

Although she had experienced effective technology use in model lessons, Tracy was concerned, based on her own technology use experience, that younger students may not be able to handle the tools. Like Evan in the previous example, Tracy associated students' developmental level with technology use when she considered whether a tool was appropriate for a specific teaching task. This consideration may indicate that the participants began to take into account student characteristics, which is one of the influencing factors for classroom technology use. If their concerns are addressed appropriately by teacher educators, such concerns can ignite more in-depth thinking in preservice teachers about how to choose appropriate technology tools for different learning tasks. 


\subsubsection{PK}

The preservice teachers' reflection on PK had the second highest coverage of all TPACK constructs. According to Mishra and Koehler, PK is "deep knowledge about the processes and practices or methods of teaching and learning and how it encompasses, among other things, overall educational purposes, values, and aims" ([2], p. 1026). The construct PK was coded in the journals whenever the preservice teachers described the use and the impact of a specific instructional strategy or technique. Thirty-three out of 39 participants (92\%) covered PK in their reflective journals. They showed some in-depth recognition of the teaching techniques, especially classrooms management skills. They began to interpret the effectiveness of a specific instructional strategy by explaining how it helped students learn. They not only described what they observed, but also tried to explain why some teaching methods would work in a classroom.

Firstly, the participants reflected extensively on classroom management skills, demonstrating deeper understanding of how and why a classroom management strategy should be used. They reflected on classroom management skills, such as learning centers, techniques to keep students focused, grouping, and providing instructions. For example, Marie discussed what she learned from her instructors about how to divide students into small groups.

For instructional strategies I learned different ways to group students together. The most obvious way is to let the students pick their own group. Another way is to assign numbers and let the students find their partners by what number complete the set. Classroom management is important to have all the activities ready and to keep the class flowing from one thing to the next. This also helps keep the students' attention.

In the above example, Marie showed some awareness that classroom management was key to effective teaching. The extensive reflection on classroom management skills may indicate the participants paid more attention to the issues with which they were concerned in a classroom. New teachers are often challenged by the organization and management of instruction [32]. As shown in Marie's comments, her instructors' effective classroom management skills had considerable impact on her. The greater focus on classroom management issues may also be due to the guiding reflection question. The instructors specifically asked the preservice teachers to pay attention to classroom management strategies and reflect on them.

Secondly, the preservice teachers began to interpret the effectiveness of a specific instructional strategy by explaining how students can benefit from it. For example, Jackie talked about how students can benefit from small group discussions.

I also thought the way we shared ideas in class was a good way. Like you said, by putting kids on the spot when asking questions, a lot of kids can be worried if they are answering in the right ways or they may not know exactly how they want to answer the question when you first ask them. By sharing in groups or writing down your answers ahead of time, discussing answers are more productive. They will have had time to think about what they want to say and they will have gotten other people's ideas. This helps with not only being able to think and answer questions but it helps with group work. A lot of kids may be 
afraid to share in front of the class. So sharing in a small group and becoming confident with your answer is something that is really positive for students.

In the above example, Jackie was aware that small group discussion can be effective in an elementary classroom. She also tried to explain how it would help students learn. By doing this, Jackie may begin to think more like expert teachers because compared to novice teachers, expert teachers would consider learning more from their students' perspective [33].

Thirdly, the preservice teachers described what they observed and tried to understand when and why to use those teaching techniques in the classroom. For example, Abby reflected on how to talk to students in a classroom.

Today in class [the teacher] talked about how she talks differently and moves around as students from all sides of the room talk during class discussions. She moved far away from a person because the student talks to the teacher. If the teacher is far away, the student will project their voice so the teacher can hear them. Since the student does this then everyone else in the classroom will listen. As [the teacher] told us this, I realized it is a good strategy and I plan on using it in my own classroom in the future.

In the above reflection, besides describing her experience, Abby explained why and how the particular instructional technique would work in a classroom. Articulating and explaining her opinion helped her understand more the appropriate instructional situations when these techniques or strategies should be used. Preservice teachers' reflection is an important step to index their learning experiences in order to reuse what they have learned [21]. The more "embellished" ([22], p. 60) their interpretation of their experiences, the more accessible the knowledge constructed through that interpretation; and the better the old experience is interpreted, the more useful the experience is in guiding reasoning in future problem-solving [22].

\subsubsection{TPACK}

The preservice teachers' reflection on TPACK, the knowledge of the complex and dynamic relationship of technology, pedagogy, and content [2], had the third highest coverage of all components. The researcher and the coder coded TPACK whenever the preservice teachers described the use and impact of technology in a learning activity for teaching specific contents. Twenty-eight participants $(72 \%)$ covered TPACK in their journals. Their reflection showed some evidence of their initial awareness in TPACK development.

After observing how to effectively use technology in a model lesson, the participants were able to articulate their technology integration experiences by recounting their observation. For example, Fay retold how she learned about caribous by researching information on a website and then playing a computer game with information from that research.

On one of the games that I played with animals, students would have to read background information about animals and then they got to use the information and knowledge that they gained in making their own story about the travel of caribou. I thought that this game was fantastic in helping students learn how to do background information and in helping them use what they have learned in assignment. Through playing this game and many other 
games on the Delicious website I began to realize that technology would be a great thing to incorporate into an elementary curriculum.

After she learned about caribous using the Internet, Fay was able to recount this piece of learning experience in her reflection. Preservice teachers often have limited technology use experience in real classrooms [34] or have limited opportunities to observe effective classroom technology use when they are K-12 students [35]. After the participants experienced effective teaching with technology in the technology integration course, retelling the learning can help further internalize their experience. This internalization can be essential to helping preservice teachers understand how to teach with technology.

The preservice teachers not only recounted their experiences, but also tried to adapt those experiences for their own teaching contexts. For example, in a Microsoft Excel model lesson, the participants used Excel to create a mini survey, collect and analyze data, and chart the data. Amy talked about how she could adapt this activity in her classroom to teach other content.

...creating the "What is your favorite kind of candy" chart and graph is an activity that different grade levels can do. The activity allows the students to move around by entering their data or collecting data from their classmates to enter into their computer. Excel is a tool students can also use to double check their findings if they wrote the numbers and graph on paper first. If when they plug in their numbers, the graph and chart look similar to the one they wrote, they know they analyzed the data correctly. Charts and graphs and Excel can be used to teach students about different habitats, sizes of animals, dates in history, or vocabulary words. Students as young as kindergarten could use Excel as long as the instructions are modified for each student's needs.

The participants had limited field experience. They did not have many opportunities to test their ideas in real classrooms. Reflection, the "imaginative action" ([10], p. 107), gave them opportunities to construct their own theory about teaching with technology by explaining why and how to use the strategies in a classroom context. They firstly had to retrieve what was learned and then fit it into a context they anticipated to be appropriate. In her reflection, Amy was able to not only retell her experience, but also go one step further to apply what she had learned in the Excel lesson to her future classroom. This imaginative act gave her an opportunity to encounter an experience in multiple contexts, which could make the knowledge acquired "more accessible, flexible, deeply learned and accurate" ([22], p. 63).

\subsection{Limited Reflection in TK, CK, TCK, and PCK}

Compared with their rich and vivid reflection in TPK, PK, and TPACK, the participants' reflection in TK, CK, TCK, and PCK was limited and superficial. The total coverage of TK, CK, TCK, and PCK in their reflection was $5.62 \%$, which was much less than that of TPACK, the third highest coverage of all TPACK constructs.

\subsubsection{TK}

The construct TK had 3.56\% coverage in the reflective journals. Mishra and Koehler defined TK as "knowledge about standard technologies" ([2], p. 1027). The researcher and the coder coded TK 
whenever the preservice teachers described a specific technology tool or resource. Twenty-eight participants (72\%) covered TK in their journals. Although many preservice teachers talked about their TK, they merely mentioned the technology tools or briefly described them without providing more details about the tools. For example, Abby described her knowledge of two assistive technology tools. She said, "Pix Writer and Board Maker used pictures and words to help children read." When reflecting on their technology knowledge, the participants tended to talk about the technology tools that were novel to them or with which they had little to no experience, such as Microsoft Excel, video conferencing, and assistive technologies. For example, Amy distinguished asynchronous and synchronous communication in her reflection.

Today in class we started off by brainstorming different types of communications and deciding if they were asynchronous or synchronous. Asynchronous communication occurs at different times and synchronous communication is communication that exists or occurs at the same time.

Detailed reflection on TK, such as Amy's, was rare. However, the fact that the preservice teachers did not reflect much on their TK may not indicate that their TK did not grow. This course introduced general technologies with which the participants were mostly familiar. They did not spend time reflecting on technologies with which they were familiar, but were inclined to write about the technology tools about which they had little knowledge. Interviews with the participants confirmed this point. The preservice teachers said they chose to write about the technology tools with which they were less familiar. Therefore, TK occupied only a small portion (3.56\%) of their reflection, since they knew about how to use most of the technology tools before taking the course.

\subsubsection{CK, TCK, and PCK}

In the journals, the preservice teachers had limited reflection on CK, PCK, and TCK. Except for TPACK, the intersections that were related to content knowledge, TCK (1.35\%), PCK (0.71\%) and CK $(0 \%)$, were mentioned little in the preservice teachers' reflective journals. Even when the participants described their content knowledge, most of their reflection was superficial. They only mentioned technology could be used to teach a certain subject or topic, without analyzing how and why the technology was suitable for that subject or topic. For example, although Amy had rich reflection in other TPACK constructs, her reflection on the content aspect was limited: "Today I learned that technology can be integrated in the classroom for a variety of subjects such as spelling, history, and mathematics." Brandy wrote, "I learned that technology can be used to teach any subject: math, history, science, reading, and writing." The above reflections were typical.

Although most participants had insufficient articulation in the content aspect of TPACK, some of them demonstrated a slightly deeper understanding about the relationship between content and technology. In their reflection, they elaborated on how technology could help their students learn content. For instance, Tracy discussed what CoWriter could help her students learn. CoWriter is an assistive technology program for writing, which has the word prediction feature.

I enjoyed CoWriter because all kids could use it. The prompt for spelling help can let students actually work on writing structures instead of spelling which can hold a lot of 
children back in terms of vocabulary. This program could help students show what they are thinking beyond what they might be able to spell. I know I always brought down writing assignments because I could not spell the big words that I was thinking.

In this example, Tracy was able to point out with the word prediction feature CoWriter was more suitable for teaching "writing structures instead of spelling". This observation showed her awareness of TCK, "the manner in which technology and content are reciprocally related" ([2], p. 1028).

The participants' superficial and limited reflection on the content aspect of TPACK may indicate they developed some understanding that technology can be used to teach different subjects. However, the participants' content knowledge may not be strong enough for them to elaborate on how and why various technologies can be used to teach a subject or topic. This group of preservice teachers were in the beginning stage of their teacher training and were developing their CK. Based on the literature, preservice teachers need help in developing both PK and CK [36]. The participants learned CK mainly in courses focusing on various subject areas and learned PK mainly in method courses. In technology courses like this one, they may focus more on the technological and pedagogical aspects, but did not direct enough attention to CK. In the abovementioned TPACK survey study [31], this group of preservice teachers did not perceive that their $\mathrm{CK}$ grew as a result of taking this course. Although the preservice teachers perceived that their TCK and PCK increased in the survey study, they did not articulate their TCK and PCK in their journals probably due to the focus and nature of this technology course.

The participants' superficial and limited reflection on the content aspect of TPACK may also due to the design of the reflection questions. The questions did not direct the participants' attention to reflecting on the content being taught in the model lessons and mini projects. Therefore, it was possible that the participants did not reveal their knowledge about the actual subject matter being taught in the reflective journals.

\subsection{How did Reflection Help the Preservice Teachers Develop TPACK?}

As an instructional strategy, reflection was designed in the LBD environment to help the preservice teachers deeply process their learning experiences, thus constructing their personal knowledge about how to integrate technology into their teaching practice, i.e., TPACK. To understand how reflection helped the participants develop TPACK, the researcher asked the participants whether and why they thought reflection was helpful for their leaning in the technology integration course. From the 38 successfully recorded interviews, 37 participants (97\%) agreed that writing reflective journals was helpful. They explained reflection helped them remember what they learned in class and pushed them to think about how to apply what they learned in their future classrooms. Some also reported their reflection became more reflective and in-depth as they wrote more about their class experiences.

Reflection helped the participants remember what they learned by describing and elaborating on their in-class experiences. Eighteen participants (47\%) mentioned reflection helped them remember what they learned in class. In the reflection, the participants "summed up what exactly [they] learned". More specifically, as Rachel said, they "summarized what the activity was", expressed whether they "thought it was good or not", and "talked about how [they] thought [they] could use it or what [they] thought the students would be taking away from using that piece of technology". Although many of the 
participants merely repeated and described the in-class activities, doing this seemed to help "stick" what was taught in their minds. Beth described this aspect with greater detail,

I think the reflection was good because it was due the next day and everything was fresh in your mind, and you can get a real statement out of it...I always wrote kind of a lengthy thing just so I could remember what we did. So that was good now I have those. If I ever need to create a portfolio or something, [I can] go back and see what I had learned.

Ella also said,

...that was very good because it's fresh in your mind so you could really write a proper reflection... a couple weeks later when you forget, you can go back to your paper and say, "Now what did we do?" And because it is so detailed cause you remembered at the time, you were able to actually go back and understand what you did.

Keeping a record of what they did in class through reflection helped both Beth and Ella remember what they learned about teaching with technology. Their in-class learning experiences were made explicit in the reflection, which may have remained tacit otherwise. As predicted in the literature [16,22], when both Beth and Ella described how the instructional events unfolded in class, they could deepen their understanding about teaching with technology. The elaboration of their in-class learning experiences could also contribute to more successful transfer in their future application of the knowledge. Based on the conversations with the participants, a couple of elements emerged that may help them articulate their experience in the reflection:

a. The instructors' guidance directed the participants' attention to key elements about teaching. The participants did not reflect on every activity. They were more attentive to the instructional strategies on which their instructors asked them to reflect. For example, Cindy said,

... I liked how she had us look at the instructional strategies and everything so that made me realize the little things that she is doing that I wouldn't usually pull out of a class that I'm sitting in...just like if I was in a different class, I wouldn't really realize that they were doing that. It makes me look at it and because I have to go and reflect on it, so I need to pick out those points and it makes me really tune into those, to what she is doing.

As it is evident from her reflection above, Cindy was more aware of the instructional strategies being modeled in class because of the instructors' guidance. There were many aspects of teaching in one activity. The instructors' pointing out the key elements seemed to help Cindy sort out her experiences. Indexing one's experience is key to reusing what has been learned [21]. Providing guidance can be necessary in assisting preservice teachers to dissect their experience.

$b$. The preservice teachers chose to discuss their learning when they felt a strong connection to the learning activities. For example, Megan said,

...normally I would be writing the reflection [by] jotting down notes on paper while the lesson was going on and the things that I thought were interesting. That was good at least to just think back because in a lot of my reflections, I actually wrote down what I 
personally would want to do as a teacher or things that I found particularly interesting. So yeah, it was good just to look back at everything I learned.

Personal and professional experiences are central to reflection [15]. Megan reflected on the course activities based on her personal style or preference as a teacher. A few other preservice teachers also mentioned that they reflected on the activities to which they could connect. This finding indicated the importance of creating a learning environment to which preservice teachers can relate their experiences.

Reflection pushed the participants to think about how to apply what they learned in their future classrooms. From the recorded interviews, ten participants (26\%) mentioned reflection was helpful for their learning in this regard. As Chris put it, "I thought that was good that we already started thinking about what we would do in our own classrooms with that." For example, Bailey said, "When I actually start writing it, I think, 'Oh I can use this, this way in my future classroom, or I could use this or I didn't really like this, how I can change that so that it will be useful in the classroom'... so it got me really thinking like I can like integrate technology."

Fay had similar comments:

I reflected on whether I liked the technology that we used in the class, and then how I would change it to incorporate it into my class. So, I guess it helped me with that thinking, thinking about what I liked, what I don't like and then, it made me think about how I would incorporate it into my classroom.

In their reflection, both Bailey and Fay envisioned how they would use technology to teach in their future classrooms. In this stage of their teacher training, the preservice teachers had limited real-classroom teaching experience. They did not have immediate opportunities to transfer what they learned in the technology integration course to real-world teaching. Therefore, reflection, the imaginative act, gave them the chance to test in their minds the technology integration ideas they had acquired in the course. In addition, Bailey seemed to be more confident in using technology to teach after experimenting with the ideas in her mind. Scholars have found that writing reflective journals can help preservice teachers gain more confidence in teaching (e.g., [37,38]). The participants developed more confidence through reflection probably by having constant conversations with themselves and personalizing their learning experiences. For example, Callie said,

I think it was good to look at the technology I use and see, "Can I use this in my classroom?" "Would I want to?" "How would parents react to this?" Well, then I thought about that and I thought, "How would my parents react?" That's how I've grown up, you know. It's good to make it a personal situation...

In the interviews, a few preservice teachers mentioned that they asked themselves a series of questions when writing the reflection as Callie did. By having constant conversations with themselves during reflection, they were able to dissect the complexity of teaching with technology. In Callie's case, she thought about how parents would react to technology use in her classroom. This indicated she began to consider broader factors affecting classroom technology use. As the literature also indicated [3], when Callie tried to personalize what she learned by fitting the instructional events into 
her own contexts, she could take ownership of her journals and developed her personal knowledge about teaching with technology.

Reflection helped the preservice teachers be more reflective and open-minded in teaching with technology. The preservice teachers' reflection was more and more reflective and in-depth as the course went on. Frank said,

When I first started writing reflections, I just said this is what we did in class, this is the technology we used. But toward the end of the semester, toward the end of the course, I was actually writing about what we did in class and reflecting on it and what is actually good about the technology, so I was being more elaborate on the class and my reflections were just a lot better, a lot more accurate.

Grace also said,

...for the first time I was like, "Oh yeah, I liked that we did this, it will be helpful doing this." But then by the last one, I was writing a lot more and 1 was like, "Oh yeah I could use it for this, I can do this, maybe this could be used for this subject," so it was good that I was kind of opening my mind to it, not just thinking technology is just like the Internet you can use to research things. There was so much more to it than that and I would begin to write about that...

In the above quotes, both Frank and Grace described how they grew in their thoughts through writing the reflective journals. Frank was more elaborate and reflective toward the end of the course. In her reflection, Grace demonstrated open-mindedness, thinking broader and considering more possibilities in using technology to teach. Open-mindedness is, as Dewey put it, "an active desire to listen to more sides than one; to give heed to the facts from whatever source they come; to give full attention to alternative possibilities; to recognize the possibility of error even in the beliefs that are dearest to us" ([10], p. 30). Grace used to think searching for information on the Internet was the primary use of technology in a classroom. After experiencing various uses of technology in the model lessons, she was willing to accept the possibility of using technology in a variety of ways in a classroom.

However, this theme was not prevalent. Only four preservice teachers mentioned that their reflection was more in-depth toward the end of the course. However, their description of the growth in reflective thoughts seemed to be consistent with the developmental process of a reflective teacher. To understand how preservice teachers articulate, analyze, and make sense of their experiences, Hatton and Smith identified three types of reflection in a developmental sequence: Technical rationality, reflection-on-action, and reflection-in-action [9]. Technical rationality is description of events and is not reflective in essence. Reflection-on-action consists of three stages: descriptive, dialogic, and critical reflection. In descriptive reflection, preservice teachers enact reasoning often based on personal judgment or on literature; in dialogic reflection, they explore rationale for their choices by having a discourse with themselves; and in critical reflection, they survey the broader contexts to explain reasons for their decisions or actions. Reflection-in-action requires teachers to consciously think about their teaching while it is happening. Based on Hatton and Smith [9], although the participants in this study started from technical rationality and enacted mostly descriptive reflection, going through these stages in reflection was necessary to prepare neophytes to enter the professional context. 


\section{Conclusions and Implications}

In this paper, the researcher explored the preservice teachers' TPACK development as manifested in their reflective journals and how reflection helped them construct TPACK. Through content analysis of the participants' reflective journals, the researcher provided a draft description of their TPACK development by describing how they interpreted their technology use experiences in a technology course. Evidence of their initial TPACK awareness was found. The preservice teachers had rich and vivid reflection in TPK, PK, and TPACK. However, their reflection in TK, CK, TCK, and PCK was limited and superficial. Through thematic analysis of the interviews with the preservice teachers, the researcher found reflection helped the preservice teachers remember what they learned by describing and elaborating on their in-class experiences, pushed them to think about how to apply what they learned in their future classrooms, and helped them become more reflective and open-minded in teaching with technology. The results support the suggestion that cultivating reflective practices in an LBD environment can be a potential effective strategy to enhance preservice teachers' TPACK development, although more evidence is needed to further prove the effectiveness of the strategy. As Spalding and Wilson put it, "we must demystify reflection if students are to take ownership of their journals and use reflection as a vehicle for personal and professional development in the preservice year and beyond" [3].

From the results, this study also indicates a few lessons for teacher educators and researchers when they create LBD or similar project-based, learner-centered environments to help preservice teachers construct TPACK.

Firstly, guidance can help preservice teachers analyze the complex relationship among content, pedagogy, and technology knowledge in their reflection. After being engaged in a complex learning environment, learners can benefit from guidance which points their attention to the essential factors in their learning. In this study, when the instructors directed their attention to the classroom management issues, the participants yielded more detailed and thoughtful comments about classroom management strategies in their journals. While the instructors did not ask the preservice teachers to reflect on the content being taught in the model lessons and the mini projects, the participants had superficial and limited reflection on the content aspects of TPACK. Therefore, if an instructor provides more guidance on the complex relationship of content, pedagogy, and technology, preservice teachers may develop more in-depth thoughts in their reflection and may be more likely to integrate their new technology experience into their existing knowledge base, thus forming a more consolidated knowledge base and emphasizing the connection of content, pedagogy and technology. If an instructor helps preservice teachers reflect on the content aspects of TPACK, they may steer more attention to think about their CK, TCK, and PCK. If an instructor points out the influencing factors in an instructional instance, preservice teachers may encode their experience into more explicit and retrieval knowledge, which may contribute to more successful knowledge transfer. Thus, how to provide effective guidance in a project-based learning environment for preservice teachers to reflect on their technology use experience can be a good topic for future research.

Secondly, it is important to create a learning environment that encourages learners to connect their own technology or teaching experiences. In an LBD environment, learners heavily rely on their previous experience related to the topics to be learned [21]. In this study, the participants reflected 
more on their learning when they felt they had some connection to the activities. Such connections were developed from their previous learning or teaching experiences, their own teaching style, personal preference, or their expectation of their future classrooms. To encourage the development of such connections in an LBD environment, teacher educators can introduce examples from real-world classrooms and create authentic learning tasks, with which preservice teachers may connect their previous experiences as a student or future experience as a K-12 teacher. Teacher educators can also help preservice teachers personalize their learning experiences by inspiring them to use the newly learned knowledge to solve their own instructional problems, which they have previously encountered or they anticipate they would encounter in their future classrooms. Therefore, how to create an LBD environment which helps preservice teachers connect their previous and current technology and teaching experiences can be a good topic for future exploration.

Thirdly, more research is needed to investigate preservice teachers' TPACK development in an LBD environment. Scholars have argued that TPACK is "a unique body of knowledge that is constructed from the interaction of its individual contributing knowledge bases" ([39], p. 154). In this study the researcher provided a draft description of preservice teachers' beginning TPACK by exploring the individual TPACK construct development. However, this study did not describe the trend of TPACK development in the participants. Therefore, it was not able to provide evidence on the change of the development in the seven constructs, whether or not their TPACK transformed into a more integrated set of knowledge base toward the end of the course. It was also not able to provide evidence on how the individual constructs contribute to the transformation of TPACK. Studies such as that done by Koehler and his colleagues [27] can shed light on future research in this regard. After tracing the TPACK development of the participants in a design seminar, Koehler and his colleagues found that at the beginning of the seminar the participants considered "technology, pedagogy and content as being independent constructs" ([27], p. 740), while toward the end they developed "a richer conception that emphasized connections among the three knowledge bases" ([27], p. 740). Is preservice teachers' TPACK development pattern similar to that of experienced teachers as in Koehler's study? And what does the TPACK development look like in senior preservice teachers who have more real-classroom experience from having done field teaching or student teaching? Future research can help address questions in these areas.

In addition, this study relied on the participants' self-report of their own learning experiences. Their account of how they would teach with technology in their future classrooms may not translate into effective practices when they are engaged in teaching practicum in real classrooms. Therefore, it is necessary to identify the stage of preservice teachers' TPACK development and trace in a longer term whether and how preservice teachers transform their initial TPACK into a more robust and mature knowledge base, and eventually translate their TPACK into effective classroom teaching. Research on teachers' TPACK developmental progression may provide insight in this regard [39].

Finally, it is important that teacher educators consider the role of an LBD environment in helping preservice teachers enrich their TPACK in the content areas. Although scholars have acknowledged the transformative and integrated nature that distinguishes TPACK from its subsets, they have also proposed that TPACK is constructed from the interaction of its contributing knowledge bases [40]. In this study, we found the participants were able to elaborate more in the technological and pedagogical aspects of TPACK, while they demonstrated less elaborate knowledge in the content 
areas. The target course of this study was essentially about teaching, in particular, how to teach with technology. Content knowledge was taught in the context of various instructional events. In other words, it was intertwined with both technology knowledge and pedagogical knowledge. Although this was the purpose of the course, the teaching of content knowledge was not as explicit as it was in a subject matter course. As a result, it was not surprising that the participants had little reflection on the content intersections, while they reflected a lot on both the technological and pedagogical components.

However, the role of an LBD environment in enhancing the $\mathrm{C}$ component in TPACK remains unresolved. Can we assume that learners' knowledge in the content intersections will automatically contribute to the formation of TPACK? If not, what strategies should be used to enhance learners' knowledge in this regard? Or will the content subsets coevolve when a preservice teacher's TPACK forms? Discussion of these questions may also lead to reflection on the TPACK framework. Koehler and Mishra acknowledged that some intersections of TPACK received less attention than others did [41]. As they stated, "in some ways, TCK is the most neglected aspect of the various intersections in the TPCK framework" (p. 16). Is TCK neglected because it is less clearly defined than other intersections? Or is it neglected because it is difficult to teach by nature? Can the neglect affect the overall TPACK construction? Clarifying these questions may help enhance the usability of this framework and provide more insight into teachers' TPACK development.

\section{Acknowledgments}

The author would like to thank Professor Jing Lei for her valuable suggestions on revising this paper, Laurene Johnson, and Leigh M. Tolley for designing the reflection questions, and Yan Suo for her help in coding the reflective journals.

\section{Conflicts of Interest}

The author declares no conflict of interest.

\section{References}

1. Schön, D.A. The Reflective Practitioner: How Professionals Think in Action; Basic Books: New York, NY, USA, 1983.

2. Mishra, P.; Koehler, M.J. Technological pedagogical content knowledge: A framework for teacher knowledge. Teach. Coll. Rec. 2006, 108, 1017-1054.

3. Spalding, E.; Wilson, A. Demystifying reflection: A study of pedagogical strategies that encourage reflective journal writing. Teach. Coll. Rec. 2002, 104, 1393-1421.

4. Sutherland, L.; Howard, S.; Markauskaite, L. Professional identity creation: Examining the development of beginning preservice teachers' understanding of their work as teachers. Teach. Teach. Educ. 2010, 26, 455-465.

5. Shoffner, M. Personal attitudes and technology: Implications for preservice teacher reflective practice. Teach. Educ. Quart. 2009, 36, 143-161.

6. Shoffner, M. The place of the personal: Exploring the affective domain through reflection in teacher preparation. Teach. Teach. Educ. 2009, 24, 783-789. 
7. Koehler, M.J.; Mishra, P. Teachers learning technology by design. J. Comput. Teach. Educ. 2005, 21, 94-102.

8. Koehler, M.J.; Mishra, P. What happens when teachers design educational technology? The development of technological pedagogical content knowledge. J. Educ. Comput. Res. 2005, 32, 131-152.

9. Hatton, N.; Smith, D. Reflection in teacher education: Towards definition and implementation. Teach. Teach. Educ. 1995, 11, 33-49.

10. Dewey, J. How We Think: A Restatement of the Relation of Reflective Thinking to the Educative Process; D.C. Heath and Company: Lexington, MA, USA, 1933.

11. Dieker, L.A.; Monda-Amaya, L.E. Reflective teaching: A process for analyzing journals of preservice educators. Teach. Educ. Spec. Educ. 1995, 18, 240-252.

12. Francis, D. The reflective journal: A window to preservice teachers' practical knowledge. Teach. Teach. Educ. 1995, 11, 229-241.

13. Canning, C. What teachers say about reflection. Educ. Leadersh. 1991, 48, 18-21.

14. Dewey, J. Experience and Education, 60th ed.; Kappa Delta Pi: West Lafayette, IN, USA, 1998.

15. Griffiths, M.; Tann, S. Using reflective practice to link personal and public theory. J. Educ. Teaching. 1992, 18, 69-84.

16. Sparks-Langer, G.M.; Colton, A.B. Synthesis of research on teachers' reflective thinking. Educ. Leadersh. 1991, 48, 37-44.

17. Handal, G.; Lauvas, P. Promoting Reflective Teaching: Supervision in Action; Open University Press: Milton Keynes, UK, 1987.

18. Schön, D. Educating the Reflective Practitioner; Jossey-Bass: San Francisco, CA, USA, 1987.

19. Ovens, A.; Tinning, R. Reflection as situated practice: A memory-work study of lived experience in teacher education. Teach. Teach. Educ. 2009, 25, 1125-1131.

20. Han, S.; Bhattacharya, K. Constructionism, Learning by Design, and Project Based Learning. In Emerging Perspectives on Learning, Teaching, and Technology; Orey, M., Ed.; 2001. Available online: http://projects.coe.uga.edu/epltt/ (accessed on 9 July 2009).

21. Kolodner, J.L.; Camp, P.J.; Crismond, D.; Fasse, B.; Gray, J.; Holbrook, J.; Puntambekar, S.; Ryan, M. Problem-based learning meets case-based reasoning in the middle-school science classroom: Putting Learning by Design ${ }^{\mathrm{TM}}$ into practice. J. Learn. Sci. 2003, 12, 495-547.

22. Kolodner, J.L. Educational implications of analogy: A view from case-based reasoning. Am. Psychol. 1997, 52, 57-66.

23. Lu, L.; Johnson, L.; Tolley, L.M.; Gillard-Cook, T.; Lei, J. Learning by Design: TPACK in Action. In Research Highlights in Technology and Teacher Education 2011; Maddux, C.D., Gibson, D., Dodge, B., Koehler, M., Mishra, P., Owens, C., Eds.; Society for Information Technology \& Teacher Education: Chesapeake, VA, USA, 2011; pp. 47-54.

24. Lu, L.; Lei, J. Using Live Dual Modeling to help preservice teachers develop TPACK. J. Dig. Learn. Teach. Educ. 2012, 29, 14-22.

25. Berelson, B. Content Analysis in Communication Research; Hafner Publishing Company: New York, NY, USA, 1971.

26. Schwandt, T.A. The SAGE Dictionary of Qualitative Inquiry, 3rd ed.; Sage Publications: Los Angeles, CA, USA, 2007. 
27. Koehler, M.J.; Mishra, P.; Yahya, K. Tracing the development of teacher knowledge in a design seminar: Integrating content, pedagogy and technology. Comput. Educ. 2007, 49, 740-762.

28. Koh, J.H.L.; Divaharan, S. Developing pre-service teachers' technology integration expertise through the TPACK-developing instructional model. J. Educ. Comput. Res. 2011, 44, 35-58.

29. Riffe, D.; Lacy,S.; Fico, F. Analyzing Media Messages: Quantitative Content Analysis; Lawrence Erlbaum Associates, Inc.: Mahwah, NJ, USA, 1998.

30. Braun, V.; Clarke, V. Using thematic analysis in psychology. Qual. Res. Psychol. 2006, 3, 77-101.

31. Lu, L.; Lei, J. Learning by Design for Preservice Teachers Technology Preparation: How Effective is It and in What Ways? Paper presented at the 2011 American Educational Research Association (AERA) Annual Conference, New Orleans, LA, USA, 10 April 2011.

32. Lederman, N.G. Teachers' understanding of the nature of science and classroom practice: Factors that facilitate or impede the relationship. J. Res. Sci. Teach. 1999, 36, 916-929.

33. Westerman, D.A. Expert and novice teacher decision making. J. Teach. Educ. 1991, 42, 292-305.

34. Greenhow, C.; Dexter, S.; Hughes, J.E. Teacher knowledge about technology integration: An examination of inservice and preservice teachers' instructional decision-making. Sci. Educ. Int. 2008, 19, 9-25.

35. West, R.E.; Graham, C.R. Benefits and challenges of using live modeling to help preservice teachers transfer technology integration principles. J. Comput. Teach. Educ. 2007, 23, 131-141.

36. Borko, H.; Livingston, C.; McCaleb, J.; Mauro, L. Student Teachers' Planning and Post-Lesson Reflections: Patterns and Implications for Teacher Preparation. In Teachers' Professional Learning; Calderhead, J., Ed.; Falmer: London, UK, 1988; pp. 65-83.

37. Hayden, H.E. Pathways To Reflection: Exploring The Reflective Analytical Practices Of Novice Teachers. Ph.D. Dissertation, University of Nebraska Lincoln, Lincoln, NE, USA, 2010.

38. Lee, O. Facilitating preservice teachers' reflection through interactive online journal writing. Phys. Educ. 2010, 67, 128-139.

39. Niess, M. Investigating TPACK: Knowledge growth in teaching with technology. J. Educ. Comput. Res. 2011, 44, 299-317.

40. Angeli, C.; Valanides, N. Epistemological and methodological issues for the conceptualization, development, and assessment of ICT-TPACK: Advances in technological pedagogical content knowledge. Comput. Educ. 2009, 52, 154-168.

41. Koehler, M.J.; Mishra, P. Introducing TPCK. In Handbook of Technological Pedagogical Content Knowledge (TPCK) for Educators; AACTE Committee on Innovation and Technology, Ed.; Routledge: New York, NY, USA, 2008; pp. 3-29.

(C) 2013 by the author; licensee MDPI, Basel, Switzerland. This article is an open access article distributed under the terms and conditions of the Creative Commons Attribution license (http://creativecommons.org/licenses/by/3.0/). 